\title{
Modelling of mined rock thin layer disintegration taking into consideration its properties changing during compaction
}

\author{
Oleksandr Tytov ${ }^{1, *}$, Jamil Haddad $^{2}$, and Vitalii Sukhariev ${ }^{3}$ \\ ${ }^{1}$ Dnipro University of Technology, 49005, Dnipro, Yavornytskoho Ave., 19, Ukraine \\ ${ }^{2}$ Al-Balqa Applied University, Amman 11134 Jordan 15008 \\ ${ }^{3}$ Institute of Geotechnical Mechanics named by N. Poljakov of National Academy of Sciences of \\ Ukraine, 49005, Dnipro, Simferopolska Str., 2a, Ukraine
}

\begin{abstract}
The aim of the work is modelling of stressed condition of the loose mined rock thin layer between two parallel working plates of disintegrator, taking into consideration the dependences of the layer porosity and its side thrust coefficient on the main stress value with hereditary model of deformation accumulation. The equation of extreme balance of mined rock compactable thin layer is obtained for the case of its compression with partial sliding on working surfaces. It is shown, that there is no sliding in the central area of deformed zone, unlike the peripheral area. The iterative algorithm for parameters calculation of the layer stressed condition for the hypothesis of symmetric parabolic distribution of the axial normal stresses in the directions being perpendicular to the plates is developed. The distributions of the side thrust coefficient in the layer, the effective coefficient of external friction and the stresses of disintegrators working surfaces are grounded. The practical value of the research is the possibility to determine precisely the contact forces while crushing of fine-grained material taking into consideration its compactibility.
\end{abstract}

\section{Introduction}

Determination of the disintegrators operating parts rational parameters includes an important stage of mined rock and crushing elements interaction forces calculation, together with stresses distribution on their surfaces. Different models of mining rock mass substitution by an element or a set of elements, resisting to applied loadings, are used for this purpose.

The easiest models consider the deformed mined rock as a single localized mass, added by elements of elasticity, viscosity and plasticity. In order to describe the destruction of a single lump of rather hard mined rock, it is enough to use the destruction model with force changing in terms of Hooke's law up to the ultimate strength. The model also deals with the ultraboundary deformation stage, which deformation curve depends on the so called "fragility module" [1]. The elements of viscosity and plasticity are put in the calculation

*Corresponding author: alextitovalex77@gmail.com 
model for the materials featuring non-elastic deformations [2]. But, these models are phenomenological ones, so the rheological coefficients for each definite case must be determined anew on a rather complicated procedure.

Every type of technological equipment has such important factor as power efficiency [3]. One of the rational modes during disintegration of fine-grained materials is "crushing in layer". In this case, the maximum lump size is up to several times less than the gap between working surfaces [4]. This disintegration method leads to the process energy consumption reduce because of the grains destruction by shift forces, including the selective crushing along the minerals cleavage planes [5]. But, the main part of the grains relative movement directions in a loose material is influenced by its stressed condition [6], unlike destruction of the monolithic rock massif, where the directions of shift planes coincide often with the defect space orientation directions [7].

The distribution of stresses for the disintegrator flat working zone is grounded in the work [8], based on the Mohr-Coulomb model with incompressible material having constant value of the side thrust coefficient. But, further experimental research [9] has shown the sufficient ruggedization of results for such an approach, that may be explained by ignoring of the porosity decrease and the side thrust coefficient increase at the pressure growth.

This conclusion is proved in the research works $[10,11]$, where the sufficient rise of pressure leads to the side thrust coefficient approaching to one unit.

The last reasons have been taken into consideration in the work [12]. They have brought to the development of the hereditary model of loose mined rock deformation models being characterized by the following equations:

- the current porosity coefficient of the material:

$$
e=\sum_{i=0}^{u} \sum_{j=0}^{u-i} c_{i, j} \cdot e_{0}^{i} \cdot\left[\ln \left(\frac{\sigma_{1}}{\sigma_{10}}\right)\right]^{j}
$$

where $c_{i, j}$ are the coefficients corresponding to the Pascal triangle of $u$ exponent, $\sigma_{1}$ is the maximum main stress, $\sigma_{10}$ is the basic value, $e_{0}$ is the initial porosity coefficient;

- the current side thrust coefficient:

$$
\xi=1-\left(1-\xi_{0}\right) \cdot \exp \left[b_{1} \cdot \ln \left(\frac{\sigma_{1}}{\sigma_{10}}\right)+b_{2} \cdot\left[\ln \left(\frac{\sigma_{1}}{\sigma_{10}}\right)\right]^{2}+\ldots+b_{m} \cdot\left[\ln \left(\frac{\sigma_{1}}{\sigma_{10}}\right)\right]^{m}\right],
$$

where $b_{1}, b_{2}, \ldots, b_{m}$ are the approximation coefficients, $\xi_{0}$ is the basic value of the side thrust coefficient.

The results of the work have good coincidence with experimental data.

Today, the analysis of stressed condition for the bodies of complex shape or with deviations from absolutely elastic model demands application of specialized computer programs for calculations, for example [13-15]. And, for our calculation case, when the properties of mined rock change in process of the loading growth, the problem solution is possible just on the basis of special calculation algorithm with finite elements and step-bystep calculation of all stressed condition parameters and material properties.

Summing up all the above-mentioned, it is necessary to determine in this work the parameters of stressed condition of loose mined rock between two parallel working plates of disintegrator, taking into consideration dependences of the layer porosity and the side thrust coefficient on the main stress value in terms of the hereditary model of deformations accumulation, that is an actual scientific problem. 


\section{Conditions of extreme balance of the mined rock thin layer having hereditary-dependent properties during compression between rigid plates}

Let's consider the extreme balance of the material small element between two horizontal plates of disintegrator (Fig. 1).

Here $\sigma_{z}$ is the normal stress along $Z$ axis, $\sigma_{r}$ is the horizontal normal stress, $\sigma_{3}$ is the minimal main stress, $H$ is the current height of the material layer, $r$ is the distance from the central axis of the deformed zone to the element's iternal edge, $m$-indexes designate the stresses component values at the working surfaces, and $a$-indexes designate the average values on layer height.
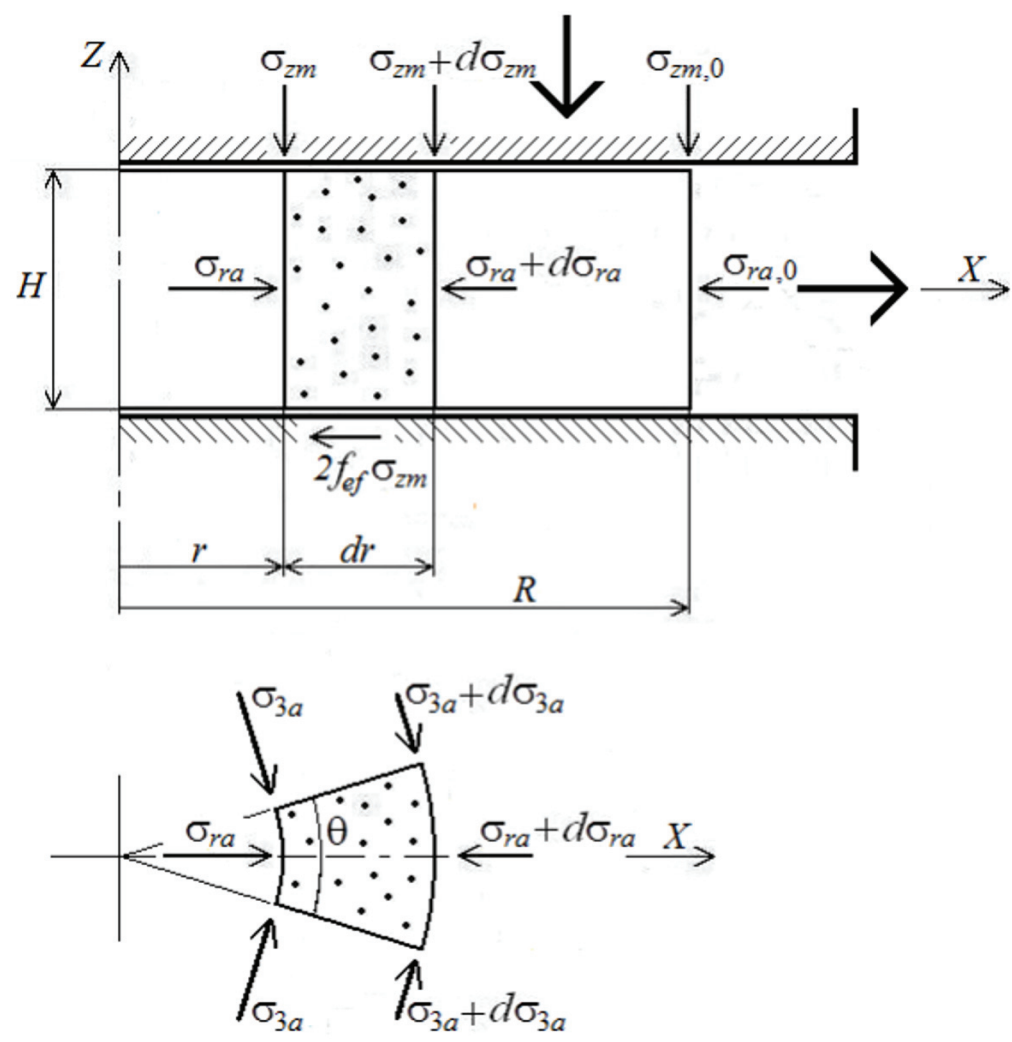

Fig. 1. Calculation scheme for the loose mined rock deformation between two rigid plates.

The following assumptions are accepted for further calculations:

1) the current porosity coefficient of material is determined by equation (1);

2) the ratio of main stresses depends on the maximum stress value and the initial porosity coefficient value:

$$
\frac{\sigma_{3}}{\sigma_{1}}=\xi\left(\sigma_{1}, e_{0}\right)
$$

for example, in accordance with equation (2);

3 ) shearing stresses in the layer are symmetric with the reversed sign concerning $X$ axis. 
According to the last assumption, the shearing stresses on $X$ axis are equal to zero, and the stresses on plates surfaces reach the values being maximum on the module and equal to

$$
\tau_{m}= \pm f_{e f} \cdot \sigma_{z m}
$$

where $f_{e f}$ is the effective friction coefficient.

The equation of the extreme balance of small element along $X$ axis (Fig. 1), in accordance to [6], should be written as follows:

$$
\frac{\partial \sigma_{r a}}{\partial r}=-\frac{2 f_{e f} \cdot \sigma_{z m}}{H}-\frac{\sigma_{r a}-\sigma_{3 a}}{r} .
$$

Here, the following expression is usable for the effective friction coefficient:

$$
f_{e f}=\left\{\begin{array}{c}
f, \quad \text { if } \quad \tan \varphi \geq f \\
\tan \varphi, \quad \text { if } \quad \tan \varphi<f
\end{array},\right.
$$

where $f$ is the friction coefficient of the mining rock sliding on the working surface; $\varphi$ is the internal-friction angle being the function of the acting maximum main stress and the initial porosity.

In this case, we don't consider the peculiarities of friction in conditions of large amount of moisture in loosened material, changing sufficiently the values of mentioned coefficients $[16,17]$.

The values of dimensionless normal stresses on axes of coordinates are developed taking into consideration (3) and (4) expressions:

$$
\begin{aligned}
& k_{z}=\frac{\sigma_{z}}{\sigma_{1}}=\frac{1+\xi+\sqrt{(1-\xi)^{2}-4 \cdot f_{e f}{ }^{2} \cdot \xi}}{2 \cdot\left(1+f_{e f}{ }^{2}\right)} \\
& k_{r}=\frac{\sigma_{r}}{\sigma_{1}}=\frac{1+\xi}{2}-\frac{1-\xi}{2} \sqrt{1-\left(\frac{2 \cdot f_{e f} \cdot k_{z}}{1-\xi}\right)^{2}} .
\end{aligned}
$$

The parabolic distributions of stresses $\sigma_{z}$ and $\sigma_{r}$ along $Z$ axis are set with extrema points located on $X$ axis (Fig. 2):

$$
\begin{aligned}
& \sigma_{z}(Z)=\sigma_{z c}+\left(\sigma_{z m}-\sigma_{z c}\right) \cdot\left(\frac{2 \cdot Z}{H}\right)^{2} ; \\
& \sigma_{r}(Z)=\sigma_{r c}+\left(\sigma_{r m}-\sigma_{r c}\right) \cdot\left(\frac{2 \cdot Z}{H}\right)^{2},
\end{aligned}
$$

where $\sigma_{z c}$ and $\sigma_{r c}$ are the axial normal stresses in the center of layer for height.

In addition, the equation of balance forces along $Z$ axis, according to [6] without material weight, looks as follows:

$$
\frac{\partial \sigma_{z q}}{\partial r}=-\frac{\partial \tau_{q}}{\partial r}-\frac{\tau_{q}}{r},
$$


where $\frac{\partial \sigma_{z q}}{\partial r}$ and $\tau_{q}$ are, correspondingly, the gradient of vertical normal stress and the shearing stress for the points located on a quarter of height from the working surfaces (they correspond to the average values for the upper or the lower half of the layer).

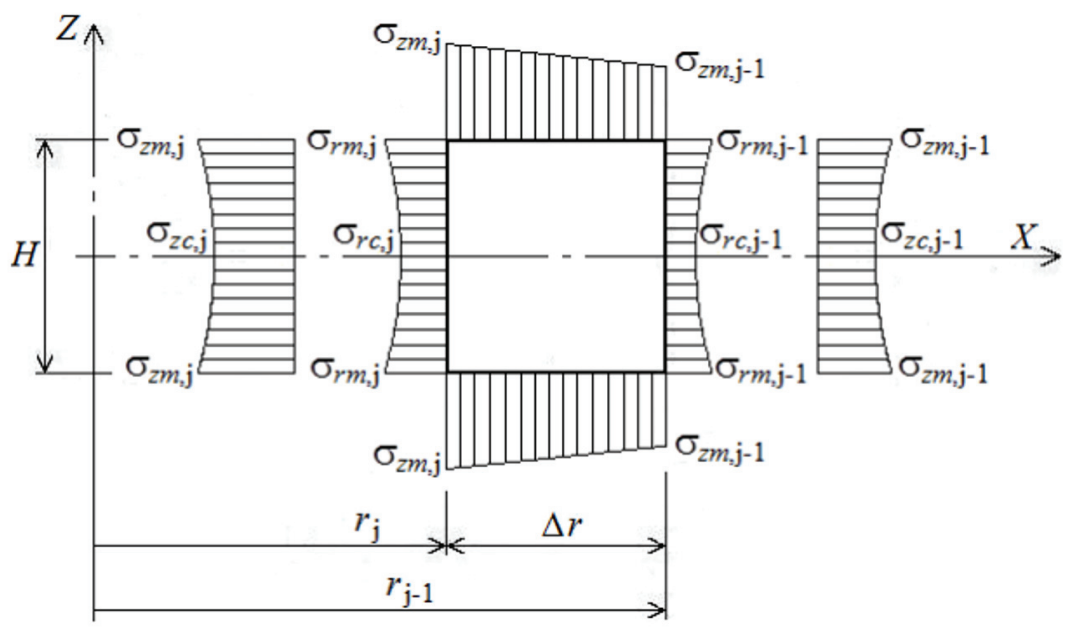

Fig. 2. Previously set diagrams of normal stresses for small element.

\section{Algorithm of stresses determination in terms of quasi-two- dimensional model}

The solving of (5) and (11) differential equations will be provided step by step, beginning from the peripheral layer to the central axis $Z$ (Fig. 1). The formulas of calculation algorithm by Euler's method of the first order with a constant step are given below as an example.

The number of calculation intervals is set equal to $n$. Some values of the initial approach of the working zone radius $r_{0}=R_{1}$ and of the corresponding to it integration step $\Delta r_{1}$ must be set for the first iterative step.

Such dependences, as $\xi=\varphi\left(\sigma_{1} ; e_{0}\right)$ and $e=\eta\left(\sigma_{1} ; e_{0}\right)$ are supposed to be previously known, together with the initial porosity values distribution

$$
e_{0}=\psi(M)
$$

where $M$ is the current material mass value, accumulated on the interval $X \in\left[r, R_{0}\right]$.

The average horizontal normal stress from equation (5) is

$$
\sigma_{r a, j}=\sigma_{r a, j-1}+\Delta r \cdot\left[\frac{2 \cdot f_{e f, j-1} \cdot \sigma_{z m, j-1}}{H}+\frac{\sigma_{r a, j-1}-\sigma_{3 a, j-1}}{r_{j-1}}\right],
$$

here, for the symmetric parabolic distributions of type (9) and (10), the following expression is acceptable:

$$
\sigma_{a}=\frac{2}{3} \sigma_{c}+\frac{1}{3} \sigma_{m}
$$


The average gradient of the vertical normal stress for a half of the layer is

$$
\frac{\partial \sigma_{z q, j}}{\partial z}=-\frac{\tau_{q, j-1}-\tau_{q, j-2}}{\Delta r}-\frac{\tau_{q, j-1}}{r_{j-1}} .
$$

The value of the horizontal normal stress on the plates surfaces is determined as follows:

$$
\sigma_{r m, j}=\frac{k_{r, j-1} \cdot\left(3 \sigma_{r a, j}-\frac{\partial \sigma_{z q, j}}{\partial z} \cdot \xi_{j-1} \cdot H\right)}{k_{r, j-1}+2 k_{z, j-1} \cdot \xi_{j-1}} .
$$

The value of the vertical normal stress on the plates surface is

$$
\sigma_{z m, j}=\sigma_{r m, j} \frac{k_{z, j-1}}{k_{r, j-1}}
$$

The maximum main stress of the plates surface is calculated in such a way:

$$
\sigma_{1 m, j}=\frac{\sigma_{r m, j}}{k_{r, j-1}}
$$

Further, the coefficients $\xi_{j}, f_{e f, j}, k_{z, j}$ and $k_{r, j}$ are calculated by the formulas given above. Also, the missing characteristic values of stresses components on the layer height are determined.

Besides, the accumulated value of the material mass, corresponding to the current coordinate value, must be calculated:

$$
M_{j}=M_{j-1}+\pi \cdot\left(r_{j-1}^{2}-r_{j}^{2}\right) \cdot H \cdot \frac{\rho}{1+e\left(\frac{\sigma_{1 a, j-1}+\sigma_{1 a, j}}{2} ; \psi\left(M_{j-1}\right)\right)},
$$

where $\rho$ is the real density of mined rock.

The total accumulated mass $M_{\text {sum }, 1}$ is known at the end of the first iteration. This value may differ from the real material mass $M_{\text {sum }}$. If the error exceeds the acceptable level, the another initial approach $R_{2}$ of external radius must be taken. The calculations proceed up to $i$-iteration with satisfactory coincidence of $M_{\text {sum }, i}$ and $M_{\text {sum }}$ values.

The total compression force can be calculated, after the final distribution of stresses on the surfaces of plates is determined:

$$
P=\sum_{j=1}^{n} \pi \cdot\left(r_{j-1}^{2}-r_{j}^{2}\right) \cdot \frac{\sigma_{z m, j-1}+\sigma_{z m, j}}{2} .
$$

\section{Results and discussion}

The quasi-two-dimensional model, allowing to determine the stresses distribution on all volume of the disintegrators flat working zone, is created based on the set of linear finite 
elements. Simple linear model, consisted only from equation (5) without equation (11), is insufficient because of the following. On the one hand, the errors of piecewise linear approximation of stresses on the working surfaces can be compensated by decrease of the integration step. On the other hand, the substitution of constant on height horizontal normal stress value in the basic equation (5) leads to the accumulation of systematic error during the following integration. So, the parabolic distributions have been applied to take into consideration the changing of normal stresses on height, and they are very similar to the distributions of real stresses.

One of the main factors, the taking of consideration of which makes scientific novelty while calculating the parameters of the stressed condition of disintegrators working zone, is the material initial porosity for a certain area. It corresponds to usage of the hereditary model of the layer deformations accumulation, mentioned in the work [12].

Another factor is the dependence of the material side thrust coefficient on the maximum main stress.

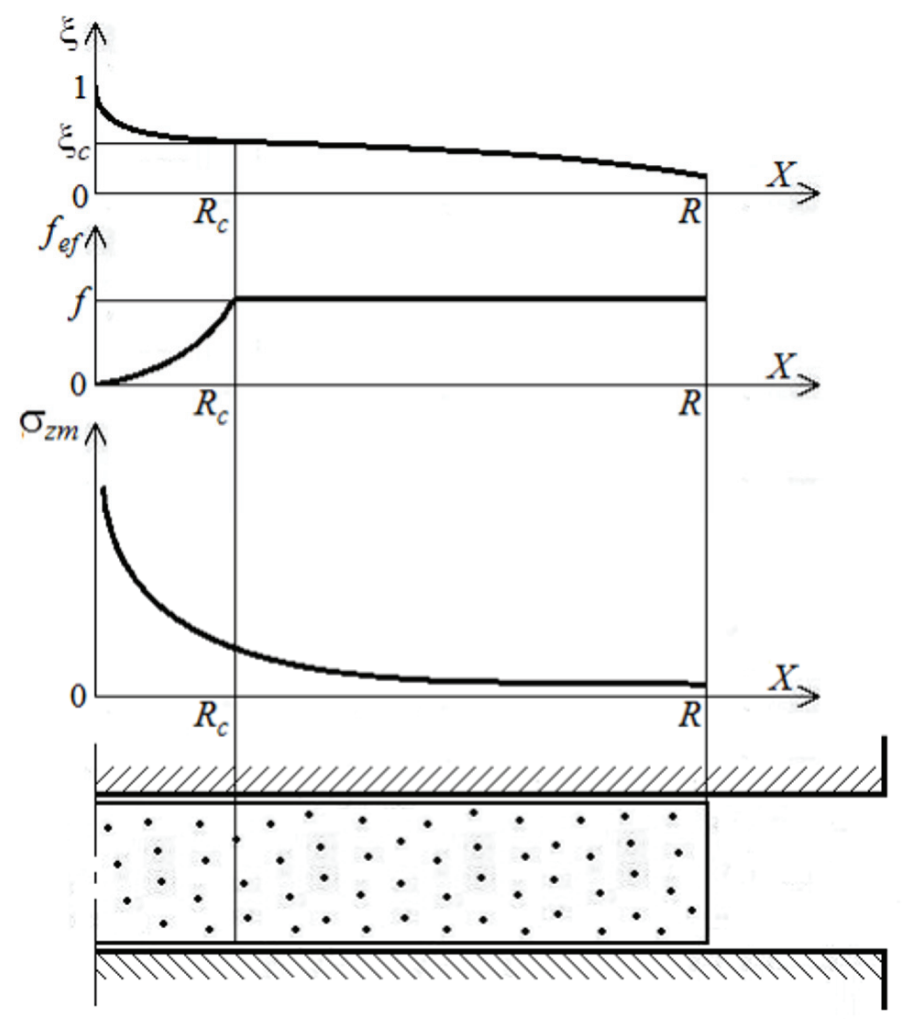

Fig. 3. Distributions of the side thrust coefficient, the effective friction coefficient and the vertical normal pressure on the disintegrator's working surfaces.

The third considered factor is the dependence for the ratio of shearing and normal stresses on the disintegrator's working surfaces on the proportion between coefficients of the external sliding friction and the material internal thrust.

It is set, that an extensive peripheral zone of deformed material is featured by conditionally low value of the side thrust coefficient combined with sliding of particles on the disintegrator's working surfaces. Also, there is rather small central zone inside $R_{c}$ radius with absence of sliding and having the side thrust coefficient more than some critical value $\xi_{c}$, depending on the maximum main stress and the initial porosity. 
The qualitative dependences of the side thrust coefficient, the effective friction coefficient and the surface vertical normal stress on the horizontal coordinate are shown in Fig. 3 (see above).

As approaching to $Z$ axis, the gradient of normal stresses increase will gain the scale of $\left(X^{-1}\right)$ and will strive to infinity for the non-limited number of calculation intervals $n$. But, the gradient of the total compression force increase will have the scale of $\left(X^{1}\right)$, so, the final value of $P$ force, determined by equation (20), will be limited value. Here, the main part of this force is concentrated just inside $R_{c}$ radius.

\section{Conclusions}

The quasi-two-dimentional model of compression by rigid plates of the loose mined rock thin layer is offered. The layer has hereditary-dependent properties, influenced mostly by the maximum main stress and the initial porosity distribution.

The algorithm for stresses components calculation in the layer, based on symmetric parabolic distributions of axial normal stresses, is developed.

The difference in the modes of material interaction with working surfaces is shown. Particles slide on the surface in the peripheral area of deformed zone, but there is no sliding in the central area.

The distributions on working surfaces of the side thrust coefficient, the effective friction coefficient and the vertical normal stress are presented.

The results of the work allow to fulfill exact calculation of the disintegrators operating parts parameters taking into consideration the continious changing of the fine-grained mined rock properties during compaction.

Authors express gratitude for the help and consultations during research performing for the head of Department of Mechanics of Mineral Processing Machines and Processes of Institute of Geotechnical Mechanics named by N. Poljakov of National Academy of Sciences of Ukraine, professor Volodymyr Nadutyi.

\section{References}

1. Shashenko, O.M., Pustovoitenko, V.P., Sdvyzhkova, O.O. (2016). Geomekhanika: Pidruchnyk dlia VUZiv. Kyiv: Novyi druk

2. Goncharevich, I.F., Frolov, K.V. (1981). Teoriya vibratsionnoy tekhniki I tekhnologii. Moskva: Nauka

3. Pivnyak, G., Samusia, V., Oksen, Y., Radiuk, M. (2014). Parameters optimization of heat pump units in mining enterprises. Progressive Technologies of Coal, Coalbed Methane, and Ores Mining, 19-24

4. Revnivtsev, V.I., Denisov, G.A., Zalrogatskiy, L.P., Turkin, V.Y. (1992). Vibratsionnaya desintegratsiya tverdykh materialov. Moskva: Nedra

5. Nadutyy, V.P., Haddad, J., Sukharyev, V.V., Loginova, A.O. (2019). The results of experimental studies of influence of variable parameters on the performance indicators of shock-centrifugal disintegrator. Naukovyi Visnyk Natsionalnoho Hirnychoho Iniversytetu, (1), 42-47

6. Dalmatov, B.I. (1988). Mekhanika gruntov, osnovaniya i fundamenty (vkliuchaya spetsialnyy kurs inzhenernoy geologii). Leningrad: Stroyizdat

7. Olovyannyi, A.G. (2012). Mekhanika gornykh porod. Modelirovanie razrusheniy. Sankt-Peterburg: OOO "Izdatelsko-poligraficheskaya kompaniya "Kosta" 
8. Nadutyy, V.P., Titov, A.A. (2016). Analiz napriazhennogo sostoyaniya ploskoy zony deformirovaniya vibratsionnykh desintegratorov $\mathrm{s}$ uchetom vybrosa materiala. Vibratsiyi v tekhnitsi ta tekhnologiyakh, 3 (83), 54-58

9. Titov, A.A. (2017). Experimental research of interrelation of mining mass layer porosity and deformation forces on flat surfaces of disintegrators. Geo-Technical Mechanics, $137,56-64$

10. Babets, D.V., Sdvyzhkova, O.O., Larionov, M.H., Tereshchuk, R.M. (2017). Estimation of rock mass stability based on probability approach and rating systems. Scientific bulletin of National Mining University, (2), 58-64

11. Sdvyzhkova, O.O., Babets, D.V., Kravchenko, K.V., Smirnov, A.V. (2016). Determining the displacements of rock mass nearby the dismantling chamber under effect of plow longwall. Scientific bulletin of National Mining University, (2), 34-42

12. Nadutyi, V., Tytov, O., Cheberiachko, I. (2018). Hereditary model of loose mined rock layer deformation in disintegrators. E3S Web of Conferences 60, 00033 (2018). Ukrainian School of Mining Engineering. DOI: 10.1051/e3sconf/20186000033

13. Kolosov, D., Dolgov, O., Kolosov, A. (2014). Analytical determination of stress-strain state of rope caused by the transmission of the drive drum traction. Progressive Technologies of Coal, Coalbed Methane, and Ores Mining, 499-504.

14. Kolosov, D., Dolgov, O., Bilous, O., Kolosov, A. (2015). The stress-strain state of the belt in the operating changes of the burdening conveyor parameters. New Developments in Mining Engineering 2015: Theoretical and Practical Solutions of Mineral Resources Mining, 585-590

15. Kolosov, D., Bilous, O., Tantsura, H., Onyshchenko, S. (2018). Stress-strain state of a flat tractive-bearing element of a lifting and transporting machine at operational changes of its parameters. Solid State Phenomena, (277), 188-201. DOI: 10.4028/www.scientific.net/SSP.277.188

16. Bondarenko, A.A. (2018). Theoretical bases of pulp suction process in the shallow dredge underwater face. Naukovyi Visnyk Natsionalnoho Hirnychoho Iniversytetu, (3), 22-29. DOI: 10.29202/nvngu/2018-3/4

17. Bondarenko, A.A. (2018). Modelling of interaction of inclined surfaces of a hydraulic classifier with a flow of solid particles. Naukovyi Visnyk Natsionalnoho Hirnychoho Iniversytetu, (4), 13-20. DOI: 10.29202/nvngu/2018-4/5 